Article

\title{
Kocurin, the True Structure of PM181104, an Anti-Methicillin-Resistant Staphylococcus aureus (MRSA) Thiazolyl Peptide from the Marine-Derived Bacterium Kocuria palustris
}

\author{
Jesús Martín ${ }^{1}$, Thiciana da S. Sousa ${ }^{1}$, Gloria Crespo ${ }^{1}$, Sara Palomo ${ }^{1}$, Ignacio González ${ }^{1}$, \\ José R. Tormo ${ }^{1}$, Mercedes de la Cruz ${ }^{1}$, Matthew Anderson ${ }^{2, \dagger}$, Russell T. Hill ${ }^{2}$, \\ Francisca Vicente ${ }^{1}$, Olga Genilloud ${ }^{1}$ and Fernando Reyes ${ }^{1}{ }^{*}$
}

1 Fundación MEDINA, Centro de Excelencia en Investigación de Medicamentos Innovadores en Andalucía, Avda. del Conocimiento 3, Granada 18016, Spain;

E-Mails: jesus.martin@medinaandalucia.es (J.M.); thicy85@yahoo.com.br (T.S.S.); gloria.crespo@medinaandalucia.es (G.C.); sara.palomo@medinaandalucia.es (S.P.); ignacio.gonzalez@medinaandalucia.es (I.G.); jose.tormo@medinaandalucia.es (J.R.T.); mercedes.delacruz@medinaandalucia.es (M.C.); francisca.vicente@medinaandalucia.es (F.V.); olga.genilloud@medinaandalucia.es (O.G.)

2 Institute of Marine and Environmental Technology, University of Maryland Center for Environmental Science, 701 E Pratt Street, Baltimore, MD 21202, USA;

E-Mails: andersomenator@gmail.com (M.A.); hill@umces.edu (R.T.H.)

$\dagger$ Current address: Algenol Biofuels, 16121 Lee Rd Suite 110, Fort Myers, FL 33912, USA.

* Author to whom correspondence should be addressed; E-Mail: fernando.reyes@medinaandalucia.es; Tel.: +34-958993965; Fax: +34-958846710.

Received: 11 December 2012; in revised form: 9 January 2013 / Accepted: 21 January 2013 / Published: 4 February 2013

\begin{abstract}
A new thiazolyl peptide, kocurin (1), was isolated from culture broths of a marine-derived Kocuria palustris. Its structural elucidation was accomplished using a combination of spectroscopic and chemical methods, including HRMS, extensive 1D and 2D NMR analysis, MS/MS fragmentation, and chemical degradation and Marfey's analysis of the resulting amino acid residues. The structure herein reported corrects that previously assigned to PM181104 (3). Kocurin displayed activity against methicillin-resistant Staphylococcus aureus (MRSA), with MIC values in the submicromolar range.
\end{abstract}


Keywords: marine-derived bacteria; Kocuria palustris; thiazolyl peptides; structure elucidation; antibacterial activity

\section{Introduction}

The increasing resistance to known antibiotics developed by bacterial pathogens is one of the greatest threats to human health worldwide. Methicillin-resistant Staphylococcus aureus (MRSA) infections have received much attention and are still a major cause of death, killing more Americans every year $(\sim 19,000)$ than emphysema, HIV/AIDS, Parkinson's disease, and homicide combined [1]. Therefore, there remains an urgent need to find new anti-MRSA antibiotics with novel modes of action.

Thiazolyl peptides constitute a class of naturally occurring compounds with potent in vitro activity against Gram-positive bacteria. The structure of these polycyclic peptides contains a central pyridine/tetrahydropyridine ring, with up to three thiazolyl substituents at the 2-, 3-, and 6-positions of the central heterocycle. This structural class includes close to 100 molecules [2], with the first member, micrococcin, isolated in 1948 [3], and some new members of the thiazomycin family reported as recently as 2009 [4]. Despite its interesting in vitro submicromolar antibacterial activity against MRSA, the development of this class of compounds as clinical agents has been hampered due to extremely poor physicochemical properties, most notably low aqueous solubility and unfavorable pharmacokinetics.

As part of our continuing program for the search of new bioactive molecules, 44 bacterial strains of the family Micrococcaceae isolated from marine sponges collected in the Florida Keys (USA) were surveyed for the presence of genes encoding non ribosomal peptide synthetase (NRPS) and polyketide synthase (PKS) enzymes and their fermentation extracts were tested for antibiotic activity against clinically relevant strains: Gram-positive bacteria (Bacillus subtilis and methicillin-resistant Staphylococcus aureus), Gram-negative bacteria (Acinetobacter baumannii) and yeast (Candida albicans). Growth inhibition of MRSA was observed in acetone extracts of three of these strains [5]. This antibacterial activity was reproduced in new fermentations and the active component, kocurin (1) (Figure 1), was isolated from one of these strains belonging to the genus Kocuria by reversed phase C18 chromatography and semipreparative HPLC, and was identified as a new member of the thiazolyl peptide family of antibiotics. The structural elucidation of kocurin was accomplished using a combination of spectroscopic and chemical methods, including HRMS, extensive 1D and 2D NMR analysis, and chemical degradation and Marfey's analysis of the resulting amino acid residues.

\section{Results and Discussion}

The producing bacterium, $K$. palustris, was fermented for 1 day in R358 medium. A 7 L fermentation was centrifuged and the cell pellet was extracted with methanol $(3 \times 50 \mathrm{~mL})$. This extract was chromatographed on a reversed phase $\mathrm{C} 18$ column using a gradient $\mathrm{H}_{2} \mathrm{O} / \mathrm{MeOH}$ and the bioactive fractions were finally purified by repeated semipreparative and preparative HPLC to yield $1.4 \mathrm{mg}$ of $\mathbf{1}$ as a white solid.

Kocurin (1) was assigned a molecular formula of $\mathrm{C}_{69} \mathrm{H}_{66} \mathrm{~N}_{18} \mathrm{O}_{13} \mathrm{~S}_{5}$ by ESI-TOF mass spectrometry $\left(m / z\right.$ 1515.3739, calc. for $[\mathrm{M}+\mathrm{H}]^{+}$1515.3733). Two absorption maxima in the UV spectrum at 218, 
307, and a shoulder at $349 \mathrm{~nm}$ together with the presence of five sulphur atoms in the molecular formula of 1 identified the compound as a member of the thiazolyl peptide class. The ${ }^{1} \mathrm{H}$ NMR spectrum (Table 1) displayed downfield singlets due to the presence of four thiazoles $(7.45,7.86,8.01$ and $8.09 \mathrm{ppm})$ and two doublets characteristic of a 2,3,6-trisubstituted pyridine ring ( 8.24 and $8.36 \mathrm{ppm})$. Other low field proton signals were attributable to protons of the aromatic rings of phenylalanine (7.17, 7.23 and 7.18 ppm) and tyrosine units $(6.45$ and $6.60 \mathrm{ppm})$. Three pairs of methylene groups resonating at 5.52 and $6.69 \mathrm{ppm}$, 5.48 and $6.54 \mathrm{ppm}$, and 5.38 and $6.58 \mathrm{ppm}$ correlated in the HSQC spectrum with carbons at 102.8, 103.6 and 103.5, respectively, accounting for three dehydroalanine residues. Correlations observed in the HMBC spectrum from these three pairs of proton signals to carbons at 133.9 and 163.1, 134.4 and 162.0, and 132.9 and 165.3 corroborated the identity of these three structural units.

Figure 1. Structures of kocurin (1), GE 37468 A (2) and PM181104 (3).

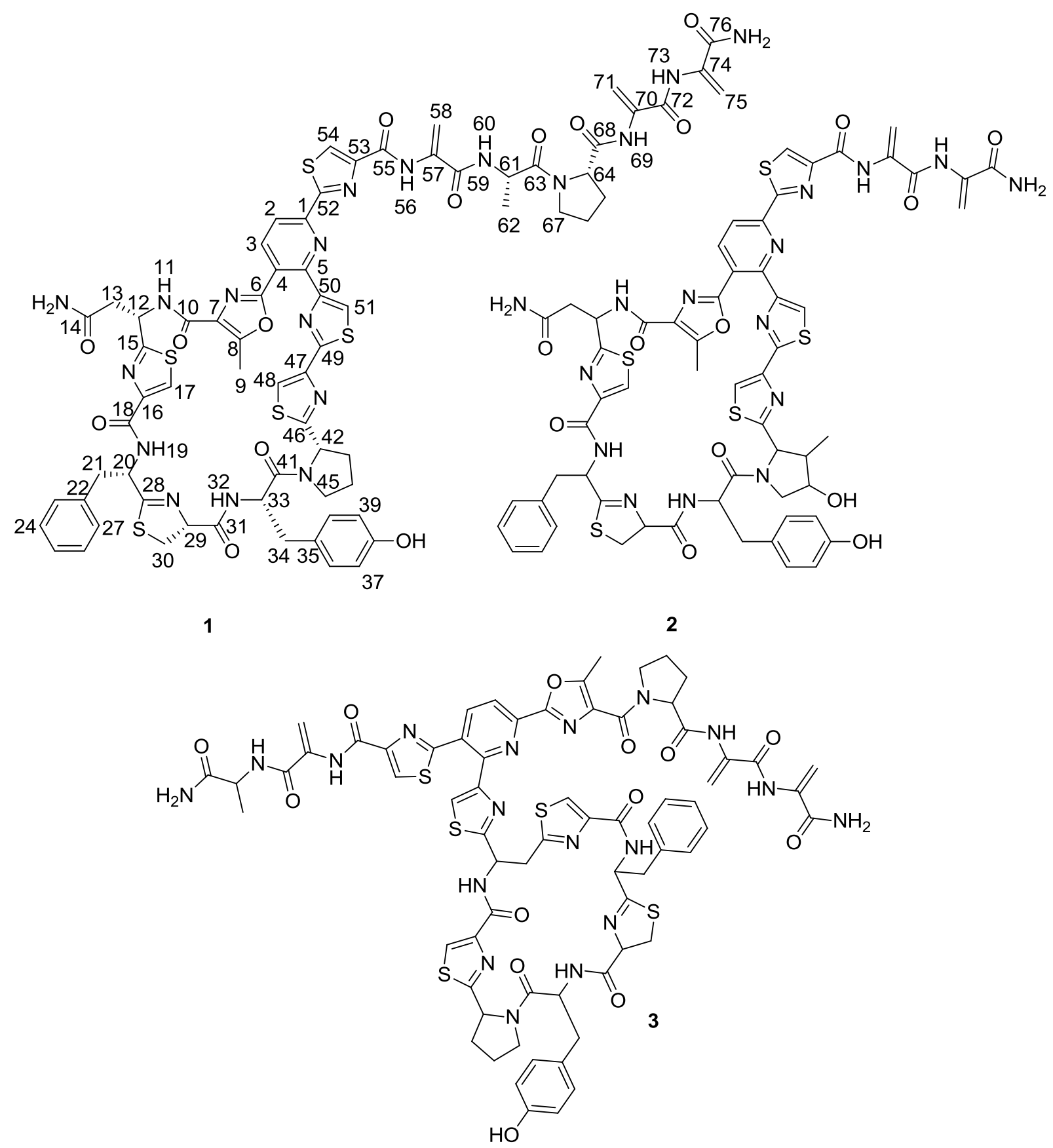


Table 1. ${ }^{1} \mathrm{H}$ and ${ }^{13} \mathrm{C}$ NMR data (500 and $125 \mathrm{MHz}, \mathrm{CDCl}_{3}$ ) for Kocurin (1).

\begin{tabular}{|c|c|c|c|c|c|}
\hline No. & $\delta(C)$ & $\delta(\mathbf{H})$, Multiplicity, $J$ & & $\delta(C)$ & $\delta(C)$, Multiplicity, $J$ \\
\hline 1 & 150.8 & & 39 & 117.6 & $6.45, \mathrm{~d}, 8.2$ \\
\hline 2 & 138.6 & $8.36, \mathrm{~d}, 8.2$ & 40 & 131.1 & $6.60, \mathrm{~d}, 8.2$ \\
\hline 3 & 118.6 & $8.24, \mathrm{~d}, 8.2$ & 41 & 170.5 & \\
\hline 4 & 122.5 & & 42 & 61.7 & $5.33, t, 7.5$ \\
\hline 5 & 151.4 & & 43 & 34.2 & $2.58, \mathrm{~m} ; 2.07, \mathrm{~m}$ \\
\hline 6 & 155.8 & & 44 & 25.7 & $2.37, \mathrm{~m} ; 2.17, \mathrm{~m}$ \\
\hline 7 & 129.9 & & 45 & 48.2 & $3.99, \mathrm{~m}, 2 \mathrm{H}$ \\
\hline 8 & 154.2 & & 46 & 173.5 & \\
\hline 9 & 12.1 & $2.88, \mathrm{~s}, 3 \mathrm{H}$ & 47 & 148.6 & \\
\hline 10 & 163.1 & & 48 & 114.0 & $7.45, \mathrm{~s}$ \\
\hline 11 & & $8.65, \mathrm{~d}, 9.7$ & 49 & 159.7 & \\
\hline 12 & 47.7 & $4.90, \mathrm{~m}$ & 50 & 154.2 & \\
\hline 13 & 37.6 & $\begin{array}{c}2.16, \mathrm{~m} \\
0.50, \mathrm{dd}, 17.4,3.0\end{array}$ & 51 & 122.5 & $8.01, \mathrm{~s}$ \\
\hline 14 & 172.3 & & 52 & 167.9 & \\
\hline 15 & 171.9 & & 53 & 151.4 & \\
\hline 16 & 149.0 & & 54 & 127.0 & $8.29, \mathrm{~s}$ \\
\hline 17 & 122.4 & $7.86, \mathrm{~s}$ & 55 & 159.4 & \\
\hline 18 & 160.3 & & 56 & & $10.05, \mathrm{~s}$ \\
\hline 19 & & $8.35, \mathrm{~d}, 6.4$ & 57 & 133.9 & \\
\hline 20 & 53.5 & $5.13, \mathrm{~m}$ & 58 & 102.8 & 6.69, br s; 5.52, br s \\
\hline 21 & 39.0 & $\begin{array}{c}3.58, \mathrm{~m} \\
3.36, \mathrm{dd}, 14.0,3.1\end{array}$ & 59 & 163.1 & \\
\hline 22 & 135.7 & & 60 & & $7.44, \mathrm{~d}, 7.4$ \\
\hline 23 & 129.9 & $7.23, \mathrm{~d}, 7.8$ & 61 & 47.6 & $4.90, \mathrm{~m}$ \\
\hline 24 & 128.4 & $7.28, \mathrm{t}, 7.8$ & 62 & 18.4 & $1.55, \mathrm{~d}, 6.8,3 \mathrm{H}$ \\
\hline 25 & 127.2 & $7.17, \mathrm{t}, 7.8$ & 63 & 172.3 & \\
\hline 26 & 128.4 & $7.28, \mathrm{t}, 7.8$ & 64 & 61.1 & $4.71, \mathrm{dd}, 7.8,3.3$ \\
\hline 27 & 129.9 & $7.23, \mathrm{~d}, 7.8$ & 65 & 27.8 & $2.38, \mathrm{~m} ; 2.09, \mathrm{~m}$ \\
\hline 28 & 172.9 & & 66 & 25.1 & $2.17, \mathrm{~m} ; 2.09, \mathrm{~m}$ \\
\hline 29 & 78.3 & $4.83, \mathrm{ddd}, 13.3,8.7,2.6$ & 67 & 47.3 & $3.71, \mathrm{~m}, 2 \mathrm{H}$ \\
\hline 30 & 35.9 & $3.76, \mathrm{~m} ; 3.58, \mathrm{~m}$ & 68 & 169.6 & \\
\hline 31 & 169.1 & & 69 & & $8.89, \mathrm{~s}$ \\
\hline 32 & & $7.40, \mathrm{~d}, 9.3$ & 70 & 134.4 & \\
\hline 33 & 51.4 & $5.21, \mathrm{~m}$ & 71 & 103.6 & $\begin{array}{l}6.54, \mathrm{~d}, 1.9 \\
5.48, \mathrm{br} \mathrm{s}\end{array}$ \\
\hline 34 & 36.4 & $\begin{array}{l}3.14, \mathrm{dd}, 14.1,3.0 \\
2.94, \mathrm{dd}, 14.1,4.5\end{array}$ & 72 & 162.0 & \\
\hline 35 & 125.6 & & 73 & & $8.86, \mathrm{~s}$ \\
\hline 36 & 131.1 & $6.60, \mathrm{~d}, 8.2$ & 74 & 132.9 & \\
\hline 37 & 117.6 & $6.45, \mathrm{~d}, 8.2$ & 75 & 103.5 & $\begin{array}{c}6.58, \mathrm{~d}, 1.4 \\
5.38, \text { br s }\end{array}$ \\
\hline 38 & 155.6 & & 76 & 165.3 & \\
\hline
\end{tabular}


Other building blocks identified in the ${ }^{1} \mathrm{H}$ NMR spectrum and confirmed via COSY, HSQC and HMBC correlations were an asparagine unit $(8.65,4.90,2.56$ and $0.50 \mathrm{ppm})$, an alanine $(7.44,4.90$ and $1.55 \mathrm{ppm})$, two prolines and a thiazoline ring $(4.83,3.76$, and $3.58 \mathrm{ppm})$. The unusual low field chemical shift of the methine carbon of the latter residue $(78.3 \mathrm{ppm})$ was due to the presence of a cyclic secondary ketimine bond in addition to the downfield effect of the adjacent carbonyl group. Finally, one methyloxazole residue was also present in the structure of $\mathbf{1}$ as revealed by the presence of a singlet methyl group at $\delta_{\mathrm{H}} 2.88 \mathrm{ppm}$ that correlated in the HMBC spectrum to 3 carbons at $\delta_{\mathrm{C}} 129.9$ (C-7), 155.8 (C-8) and 163.1 (C-10, weak, 4-bond correlation).

Once all the subunits present in the structure of the new peptide were identified, the sequence of amino acids was established by analysis of key correlations observed in the HMBC spectrum (Figure 2) and MS/MS analysis. HMBC correlations confirmed that the central pyridine nucleus was surrounded by two of the thiazolyl and the methyloxazole units and allowed the planar structure of the compound to be established as depicted in Figure 2. Additional support for the sequence determined by HMBC came from the analysis of key fragments observed in the MS/MS spectrum of the molecule. Thus, the sequence Dha-Dha-Pro-Ala for the $C$-terminal amino acid side chain was determined from fragments at $m / z 1498,1429,1360,1263$, and 1192 (Figure 2). The planar structure of kocurin was found to be similar to that of the antibiotic peptide GE 37468 A (2) [6,7], the major structural differences found between both compounds being the replacement of the methylhydroxyproline unit in the cycle of $\mathbf{2}$ by proline in $\mathbf{1}$ and the presence of additional amino acid units in the side chain of the latter compound.

Figure 2. Key HMBC correlations and MS/MS fragments observed in the spectra of kocurin (1).

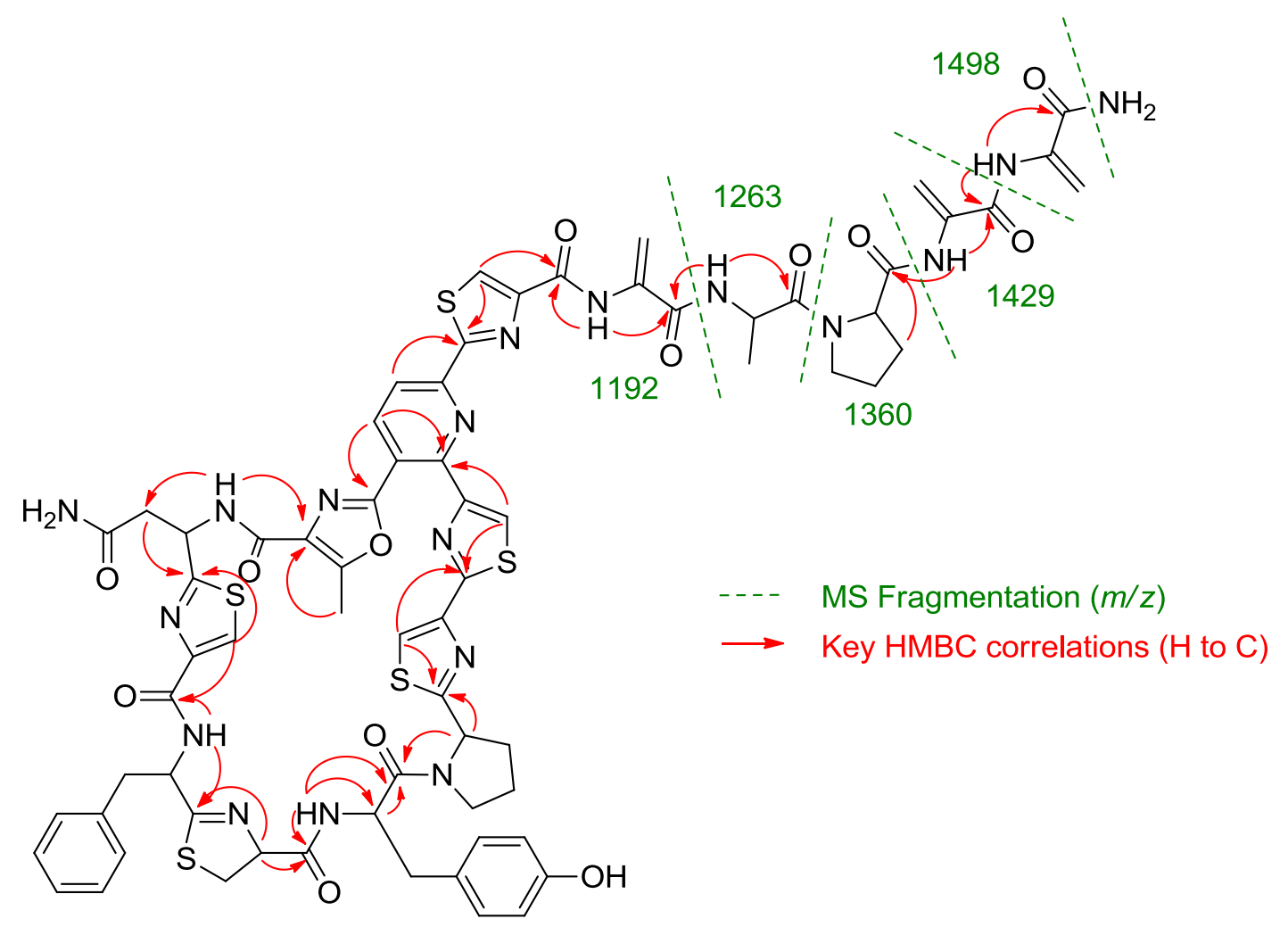


The absolute configurations of the amino acid residues in kocurin were determined by application of the Marfey's methodology [8]. A hydrolysis of the sample with $\mathrm{HCl} 6 \mathrm{~N}\left(110{ }^{\circ} \mathrm{C}\right.$, overnight) and derivatization of the hydrolysate with 1-fluoro-2,4-dinitrophenyl-5-L-valinamide (L-FDVA) revealed the presence of L-Tyr, L-Pro $(\times 1)$ and L-Ala on the basis of comparison of their retention times with those of derivatized standards. In order to liberate those amino acids adjacent to thiazole rings to determine their absolute configurations, it was necessary to cleave these by ozonolysis prior to hydrolysis. Treatment of a solution of 1 in $\mathrm{CHCl}_{3} / \mathrm{MeOH}$ with ozone for $10 \mathrm{~min}$ followed by acid hydrolysis with $6 \mathrm{~N} \mathrm{HCl}\left(110^{\circ} \mathrm{C}\right.$, overnight $)$ and derivatization with L-FDVA identified L-Asp, L-Phe, L-Cya, L-Pro $(\times 2)$ and L-Ala as components of the hydrolyzate by LC/MS. Tyr was not found in this analysis, probably due to its decomposition during the ozonization of the peptide. The ozonolysis of the sample prior to the acid hydrolysis had the additional advantage of reducing the epimerization of the thiazoline present in the molecule, which has been described to readily occur in the presence of mild acid or base. A 1.6:1 ratio of L- and D-Cya was obtained in the LC/MS analysis, confirming L-Cys as the residue present in the structure of kocurin. The L-Cys assignment was also supported by comparative ${ }^{1} \mathrm{H}$ and ${ }^{13} \mathrm{C}$ NMR data of the thiazoline in $\mathbf{1}$ to those reported for other molecules containing the same residue.

Once the complete structure of the compound had been determined, a literature search revealed the existence of two patents describing compounds having the same molecular formula as kocurin, the thyazolyl peptide PM181104 (3), isolated from a marine-derived Kocuria sp. (ZMA B-1/MTCC 5269) [9] and a molecule with the same planar structure as kocurin obtained from Kocuria sp. Strain MI-67-EC3-038, isolated from a marine sample collected in the Southeast coast of Spain [10]. Although no explanation is given in the first patent about the rationale followed in the structural elucidation of $\mathbf{3}$, we believe that kocurin and PM181104 are actually the same molecule. Although the same residues can be identified by NMR in both structures, on the basis of biogenetic grounds we firmly believe that the structure proposed for $\mathbf{3}$ is not correct, probably due to a misinterpretation of some HMBC correlations observed for carbons resonating very closely, and that the actual compound isolated in the work described in the patent has the structure herein proposed for kocurin. It is well known that thiazolyl peptides arise from a cascade of post-translational modifications on 50 to 60 residue pre-peptide precursors that trim away the $\mathrm{N}$-terminal leader sequences (40 residues) while at the $\mathrm{C}$-terminal, 14 to 18 residues are converted into the mature scaffold [11]. In this sense, kocurin would be the result of post-translational modifications of a linear C-terminal peptide containing 17 amino acids (Ser-Thr-Asn-Cys-Phe-Cys-Tyr-Pro-Cys-Cys-Ser-Cys-Ser-Ala-Pro-Ser-Ser) whereas the biosynthesis of PM181104 would require the participation of two independent peptide units of 13 (Cys-Phe-Cys-Tyr-Pro-Cys-Asp/Asn-Cys-Ser-Thr-Pro-Ser-Ser) and 4 (Ser-Cys-Ser-Ala) amino acid residues (Figure 3). A second inconsistency in the structure proposed for compound $\mathbf{3}$ is the presence of two $C$-terminal amino acids. Due to this, the MS/MS fragmentation pattern generated by this compound should contain additional ions to those observed for $\mathbf{1}$, originated by losses of amino acids from both side chains. Among others, ions at $m / z 1427$ and 1358 accounting for the elimination of the terminal alanine and alanine-DHA residues in PM181104, not observed in the spectrum of kocurin, should appear in the MS/MS spectrum of the molecule. Unfortunately, no MS/MS fragmentation of PM181104 is reported in the patent and only the molecular ion of the compound is included as part of the structural information. Finally, a comparison of the ${ }^{1} \mathrm{H}$ NMR in DMSO- $d_{6}$ of kocurin with that reported in the patent for PM181104 definitely confirms that both molecules are identical. 
The biological activity of kocurin was tested against a panel of bacterial and fungal pathogens, including wild-type MRSA and $S$. aureus strains resistant to thiazomycin, other Gram-positive (Bacillus subtilis and Enterococcus faecium) and Gram-negative (Escherichia coli, Acinetobacter baumannii and Pseudomonas aeruginosa) bacteria and one fungus (Candida albicans). Kocurin strongly inhibited the growth of MRSA MB5393 with a MIC value of $0.25 \mu \mathrm{g} / \mathrm{mL}$. In addition, the compound also displayed antibacterial activity against $B$. subtilis and E. faecium in a solid agar test, with zones of inhibition (ZOI) of 9 and $10 \mathrm{~mm}$ when tested at a concentration of $8 \mu \mathrm{g} / \mathrm{mL}$. On the other hand, the compound displayed ZOI of $5 \mathrm{~mm}$ when a $10 \mu \mathrm{L}$ aliquot of a $2 \mu \mathrm{g} / \mathrm{mL}$ solution was spotted on plates containing cultures of both, wild-type and thiazomycin resistant $S$. aureus strains, revealing that the mechanism of action of the compound is different from that of thiazomycin. Finally, kocurin did not inhibit the growth of Gram-negative bacteria or C. albicans when tested at a concentration of $16 \mu \mathrm{g} / \mathrm{mL}$.

Figure 3. Structural units required for the biosynthesis of kocurin (1) and PM181104 (3).

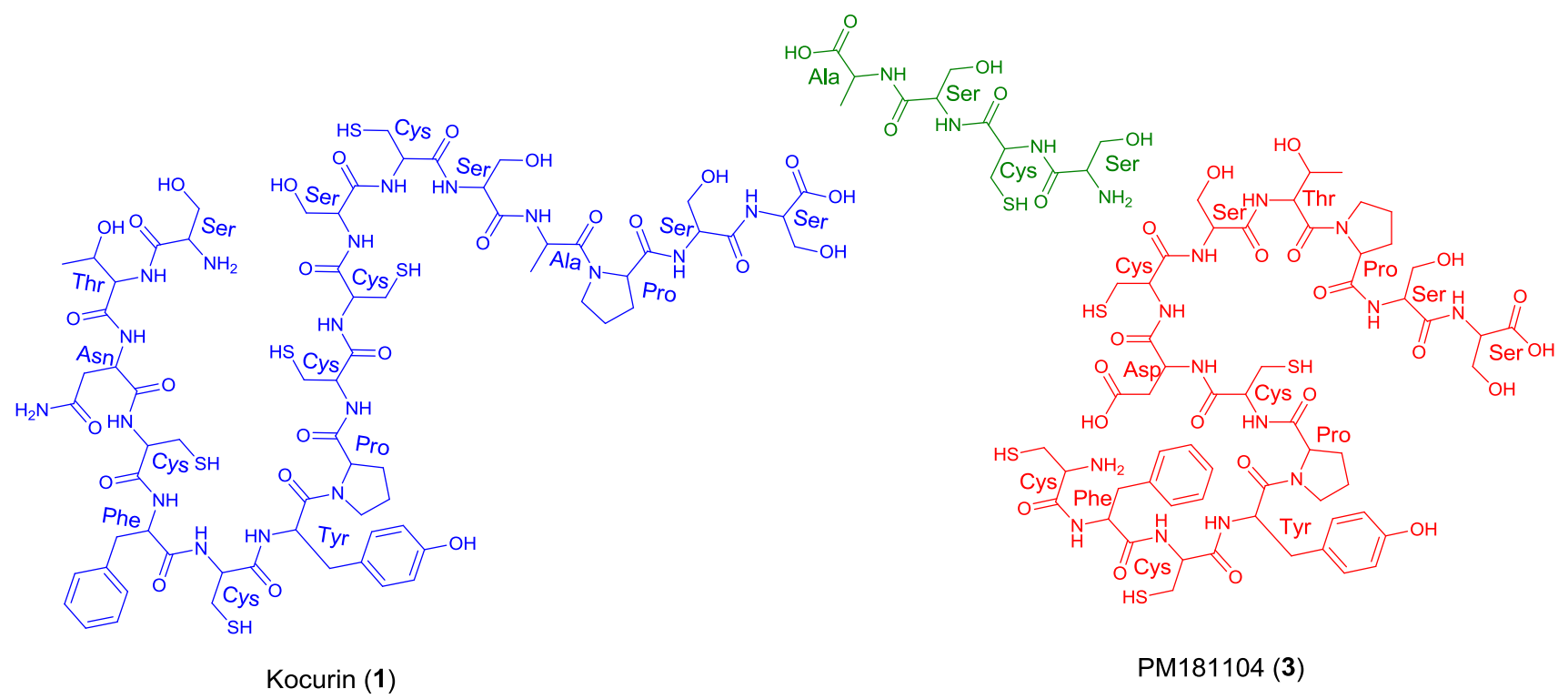

\section{Experimental Section}

\subsection{General Experimental Procedures}

Optical rotations were determined using a JASCO P-2000 polarimeter. UV spectra were obtained with an Agilent 1200 DAD. NMR spectra were recorded on a Varian "INOVA 500" spectrometer at $500 / 125 \mathrm{MHz}\left({ }^{1} \mathrm{H} /{ }^{13} \mathrm{C}\right)$. Chemical shifts were reported in ppm using residual $\mathrm{CDCl}_{3}\left(\delta 7.26\right.$ for ${ }^{1} \mathrm{H}$ and 77.0 for ${ }^{13} \mathrm{C}$ ) as internal reference. HMBC experiments were optimized for a ${ }^{3} J_{\mathrm{CH}}$ of $8 \mathrm{~Hz}$. $(+)$-ESI-TOFMS was performed on a Bruker maXis spectrometer.

\subsection{Producing Microorganism}

The producing strain F-276,345 was obtained from a sponge sample collected in Florida Keys, USA [12]. Upon phylogenetic analysis based on partial 16S rRNA gene sequences of related type species, the strain F-276,345 was identified as a new member of the species Kocuria lacustris [5]. 


\subsection{Fermentation of the Producing Microorganism}

A 7.2 liter fermentation of Kocuria palustris F-276,345 was obtained as follows: a first seed culture of the strain F-276,345 was prepared by inoculating three $50 \mathrm{~mL}$ tubes containing $12 \mathrm{~mL}$ each of MY seed medium (D-(+)-Glucose $10 \mathrm{~g} / \mathrm{L}$, Bacto Yeast Extract $3 \mathrm{~g} / \mathrm{L}$, Proteose-peptone $5 \mathrm{~g} / \mathrm{L}$, Malt Extract $3 \mathrm{~g} / \mathrm{L}$, adjusted to $\mathrm{pH} 7.0$ ), with $0.5 \mathrm{~mL}$ of a frozen inoculum stock of the producing strain and incubating the tube at $28{ }^{\circ} \mathrm{C}$ with shaking at $220 \mathrm{rpm}$ for about $24 \mathrm{~h}$. A second seed culture was prepared by inoculating eight $250 \mathrm{~mL}$ flasks containing $50 \mathrm{~mL}$ each of MY seed medium with $2.5 \mathrm{~mL}$ of the first seed. A 5\% aliquot of the second seed culture was transferred to each of the forty-eight $500 \mathrm{~mL}$ flasks containing $150 \mathrm{~mL}$ of the production medium R358, which is a modified version of the one used by Jensen et al. [13], which consists of starch from potato $10 \mathrm{~g} / \mathrm{L}$, Bacto Yeast Extract $4 \mathrm{~g} / \mathrm{L}$, Bacto Peptone $2 \mathrm{~g} / \mathrm{L}, \mathrm{FeSO}_{4} \cdot 7 \mathrm{H}_{2} \mathrm{O}(5 \mathrm{~mL}$ of a $8 \mathrm{~g} / \mathrm{L}$ stock solution), and $\mathrm{KBr}(5 \mathrm{~mL}$ of a $20 \mathrm{~g} / \mathrm{L}$ stock solution) at $\mathrm{pH}$ 7.0. The flasks were incubated at $28^{\circ} \mathrm{C}$ for 1 day in a rotary shaker at $220 \mathrm{rpm}$ and $70 \%$ humidity before harvesting.

\subsection{Extraction and Isolation}

The culture broth was centrifuged for $15 \mathrm{~min}$ at $8500 \mathrm{rpm}$ and the supernatant was discarded. The cell pellet was extracted with $\mathrm{MeOH}(3 \times 50 \mathrm{~mL})$, filtered and the solvent was evaporated to dryness. The dried extract was subjected to reversed phase flash chromatography (15.5 g of RediSep C18, gradient from $20 \% \mathrm{MeOH}$ to $100 \% \mathrm{MeOH}$ in $12.5 \mathrm{~min}+100 \% \mathrm{MeOH}$ for $10 \mathrm{~min}, 10 \mathrm{~mL} / \mathrm{min}$, UV detection at 210 and $305 \mathrm{~nm}$ ) yielding a fraction eluting between 12.5 and 14.4 min that was subjected to semipreparative HPLC (X-Bridge Phenyl, $10 \times 15 \mathrm{~mm}, 5 \mu \mathrm{m}$, gradient $\mathrm{H}_{2} \mathrm{O}-\mathrm{CH}_{3} \mathrm{CN}$ from $25 \%$ to $80 \%$ $\mathrm{CH}_{3} \mathrm{CN}$ in $35 \mathrm{~min}, 3.6 \mathrm{~mL} / \mathrm{min}$, UV detection) to yield $1.4 \mathrm{mg}$ of kocurin (1) as a white amorphous solid.

Data for kocurin (1): White amorphous solid; $[\alpha]^{25}+27.0\left(c 0.11, \mathrm{CHCl}_{3} / \mathrm{MeOH} 1: 1\right)$; UV (DAD) $\lambda_{\max } 218,307,349$ (sh) nm; IR (ATR) $v_{\max } 3342,2922,2853,1649,1512,1427 \mathrm{~cm}^{-1} ;{ }^{1} \mathrm{H}$ and ${ }^{13} \mathrm{C}$ NMR: see Table 1; (+)-ESI-TOFMS m/z 1515.3739 [M+ H] ${ }^{+}$(calc. for $\mathrm{C}_{69} \mathrm{H}_{66} \mathrm{~N}_{18} \mathrm{O}_{13} \mathrm{~S}_{5}, 1515.3733, \Delta 0.3 \mathrm{ppm}$ ).

\subsection{Ozonolysis, Acid Hydrolysis, and Marfey's Analysis of Kocurin (1)}

A sample of kocurin $(0.1 \mathrm{mg}, 50 \mathrm{mM})$ was treated with $6 \mathrm{~N} \mathrm{HCl}$ in a sealed vial at $110{ }^{\circ} \mathrm{C}$ for $24 \mathrm{~h}$. The solution was concentrated to dryness in vacuo. The hydrolysate was reconstituted in $\mathrm{H}_{2} \mathrm{O}(50 \mu \mathrm{L})$ and treated with a solution of 1-fluoro-2,4-dinitrophenyl-5-L-valine-amide (L-FDVA, $150 \mu \mathrm{L}, 1 \%$ in acetone) and a $1 \mathrm{M}$ solution of $\mathrm{NaHCO}_{3}(20 \mu \mathrm{L})$ in a sealed vial at $40{ }^{\circ} \mathrm{C}$ for $1 \mathrm{~h}$. The reaction mixture was neutralized with $1 \mathrm{~N} \mathrm{HCl}(20 \mu \mathrm{L})$ and an aliquot $(10 \mu \mathrm{L})$ was diluted with $\mathrm{CH}_{3} \mathrm{CN}(40 \mu \mathrm{L})$. The resulting solution was analyzed by LC-MS employing a Waters X-Bridge C18 column $(4.6 \times 150 \mathrm{~mm}$, $5 \mu \mathrm{m})$ and a gradient elution profile of $10 \% \mathrm{~B}\left(90 \% \mathrm{CH}_{3} \mathrm{CN}, 10 \% \mathrm{H}_{2} \mathrm{O}, 1.3 \mathrm{mM}\right.$ TFA, $1.3 \mathrm{mM}$ ammonium formiate)/90\% $\mathrm{A}\left(10 \% \mathrm{CH}_{3} \mathrm{CN}, 90 \% \mathrm{H}_{2} \mathrm{O}, 1.3 \mathrm{mM}\right.$ TFA, $1.3 \mathrm{mM}$ ammonium formiate $)$ to $55 \% \mathrm{~B} / 45 \%$ A over $35 \mathrm{~min}$ at flow of $1 \mathrm{~mL} / \mathrm{min}$. The hydrolysate of kocurin contained L-Ala (13.7 min), L-Pro (14.9 $\mathrm{min}$ ) and L-Tyr (30.5 min). The retention time of the L-FDVA derivatives of the authentic amino acids were as follows: L-Ala (13.8 $\mathrm{min})$, D-Ala (18.3 $\mathrm{min})$, L-Pro (14.9 min), D-Pro (18.1 min), L-Tyr (30.6 min) and D-Tyr (34.8 $\mathrm{min})$. 
A second sample $(0.2 \mathrm{mg})$ of the peptide was dissolved in $2 \mathrm{~mL}$ of $\mathrm{CHCl}_{3} / \mathrm{CH}_{3} \mathrm{OH}$, and ozone was bubbled through the solution for $10 \mathrm{~min}$. This solution was evaporated to dryness on a rotary evaporator. Subsequent hydrolysis and Marfey's analysis of the resulting residue was performed as described above. The resulting solution was analyzed by LC-MS employing a Waters X-Bridge C18 column $(4.6 \times 150 \mathrm{~mm}$, $5 \mu \mathrm{m}$ ) and a gradient elution profile of $10 \% \mathrm{~B} / 90 \% \mathrm{~A}$ to $35 \% \mathrm{~B} / 65 \% \mathrm{~A}$ over $35 \mathrm{~min}$ and then to $100 \% \mathrm{~B}$ in $1 \mathrm{~min}$ and held at $100 \% \mathrm{~B}$ for $4 \mathrm{~min}$ using a flow of $1 \mathrm{~mL} / \mathrm{min}$. The hydrolysate of the ozonolysis product gave L-Ala (19.0 min), L-Asp (14.1 min), L-Phe (35.2 $\mathrm{min}$ ) and L-Pro (21.4 min). The retention time of the L-FDVA derivatives of the authentic amino acids were as follows: L-Ala (19.0 min), D-Ala (28.5 min), L-Asp (14.1 min), D-Asp (16.4 min), L-Phe (34.6 min), D-Phe (37.8 min), L-Pro (20.8 min) and D-Pro (27.3 min). A second chromatographic method using the same solvent system as the previous methods (Waters X-Bridge C18 column $(4.6 \times 150 \mathrm{~mm}, 5 \mu \mathrm{m})$ and isocratic elution $3 \% \mathrm{~B} / 97 \%$ A over $35 \mathrm{~min}$ at flow of $1 \mathrm{~mL} / \mathrm{min}$ ) was used for the identification of the L-Cya residue (17.4 $\mathrm{min})$ (Cya L:D, 1.5:1). The retention times of the L-FDVA derivatives of cysteic acid were: L-Cya (17.4 min), D-Cya (18.5 min).

\subsection{Antifungal Assays}

Frozen stocks of $C$. albicans were used to inoculate Sabouraud Dextrose Agar (SDA) plates for confluent growth. Plates were incubated for $24 \mathrm{~h}$, at $35^{\circ} \mathrm{C}$. The grown colonies were harvested from the SDA plates and suspended in RPMI-1640 modified medium. Modified RPMI-1640 medium was prepared as follows: $20.8 \mathrm{~g}$ of RPMI powder (Sigma) were poured into a $2 \mathrm{~L}$ flask, together with $13.4 \mathrm{~g}$ of YNB, 1.8 L of milliQ water, $80 \mathrm{~mL}$ of $1 \mathrm{M}$ HEPES and $72 \mathrm{~mL}$ of glucose $50 \%$. The volume was adjusted to $2 \mathrm{~L}$ and filtered. The $\mathrm{OD}_{660}$ was adjusted to 0.25 using RPMI-1640 modified as diluent and blank. This inoculum was diluted 1:10 and kept on ice until used to inoculate 96-well microtiter plates. For the assay, $90 \mu \mathrm{L} /$ well of the 1:10 diluted inoculum were mixed with $1.6 \mu \mathrm{L} /$ well of compound solution in DMSO and $8.4 \mu \mathrm{L} /$ well of RPMI-1640 modified medium. Amphotericin B and Penicillin G were used as internal positive and negative controls respectively. After dispensing the inocula, the samples and the controls, the assay plates were read in a Tecan Ultraevolution spectrophotometer at $612 \mathrm{~nm}$ for $T_{0}$ (zero time). Then, the plates were statically incubated at $37^{\circ} \mathrm{C}$ for $20 \mathrm{~h}$. After incubation, the plates were shaken in a DPC Micromix-5 and read again for $T_{f}$ (final time). Percentage of growth inhibition was calculated using the following equation:

$\%$ Inhibition $=100 \times\left\{1-\left[\left(T_{\mathrm{f} \text { Sample }}-T_{0 \text { Sample }}\right)-\left(T_{\mathrm{f} \text { Blank }}-T_{0 \text { Blank }}\right)\right] /\left[\left(T_{\mathrm{f} \text { Growth }}-T_{0 \text { Growth }}\right)-\right.\right.$ $\left.\left.\left(T_{\mathrm{f} \text { Blank }}-\mathrm{T}_{0 \text { Blank }}\right)\right]\right\}$

Compound 1 was serially diluted in DMSO with a dilution factor of 2 to provide 10 concentrations starting at $160 \mu \mathrm{g} / \mathrm{mL}$. The MIC was defined as the lowest concentration of an antimicrobial or antifungal compound that inhibited $\geq 95 \%$ of the growth of a microorganism after overnight incubation. The data were analysed using the Genedata Screener program (Genedata AG, Switzerland). In all experiments performed in this work the RZ' factor obtained was between 0.85 and 0.95 . 


\subsection{Antibacterial Assays}

For the liquid media antibacterial tests, thawed stock inocula suspensions from cryovials of each microorganism (MRSA, A. baumannii, E. coli and P. aeruginosa) were streaked onto Luria-Bertani agar plates (LBA, $40 \mathrm{~g} / \mathrm{L}$ ) and incubated at $37{ }^{\circ} \mathrm{C}$ overnight to obtain isolated colonies. Single colonies of each microorganism were inoculated into $10 \mathrm{~mL}$ of Luria-Bertani broth medium (LB, $25 \mathrm{~g} / \mathrm{L}$ in $250 \mathrm{~mL}$ Erlenmeyer flasks) and incubated overnight at $37^{\circ} \mathrm{C}$ with shaking at $220 \mathrm{rpm}$ and then diluted in order to obtain assay inocula of approximately $1.1 \times 10^{6} \mathrm{CFU} / \mathrm{mL}$ (MRSA) or 5-6 $610^{5} \mathrm{CFU} / \mathrm{mL}$ (A. baumannii, E. coli and P. aeruginosa).

For the assay $90 \mu \mathrm{L} /$ well of the diluted inoculum were mixed with $1.6 \mu \mathrm{L} /$ well of each compound dissolved in DMSO and $8.4 \mu \mathrm{L} /$ well of LB medium. Kanamycin and amphotericin B (MRSA), rifampicin and amphotericin $\mathrm{B}$ (A. baumannii), novobiocin and amphotericin $\mathrm{B}$ (E. coli), and ciprofloxacin and amphotericin B (P. aeruginosa) were included as internal plate controls. Absorbance at $612 \mathrm{~nm}$ was measured with a Tecan UltraEvolution spectrophotometer (Tecan, Durham, USA) at $T_{0}$ (zero time) and immediately after that, plates were statically incubated at $37{ }^{\circ} \mathrm{C}$ for $20 \mathrm{~h}$. After this period, the assay plates were shaken using the DPC Micromix-5 and once more the absorbance at OD $612 \mathrm{~nm}$ was measured at $T_{f}$ (final time). Percentage inhibition of growth was calculated using the same equation previously described for $C$. albicans.

Assays in solid agar plates were performed in order to determine the antimicrobial susceptibility of kocurin against $B$. subtilis MB964, E. faecium MB5571 resistant to vancomycin and $\beta$-lactam antibiotics and thiazomycin-resistant $S$. aureus strains. The B. subtilis MB964 assay plates were prepared by adding $1 \mathrm{~mL}\left(1.5 \times 10^{8} \mathrm{CFU} / \mathrm{mL}\right)$ of a spore suspension (Difco) directly to 1 liter of cooled nutrient agar yeast extract medium (NAYE, nutrient agar $23 \mathrm{~g} / \mathrm{L}$, yeast extract $2 \mathrm{~g} / \mathrm{L}$ ). The E. faecium strain was grown in a shaken $(220 \mathrm{rpm})$ culture of brain heart infusion broth $(\mathrm{BHI}, 37 \mathrm{~g} / \mathrm{L})$ at $37{ }^{\circ} \mathrm{C}$. The assay plates were prepared by inoculating the same cooled media plus agar $(15 \mathrm{~g} / \mathrm{L})$ with $3.3 \%$ of the inoculum adjusted to an optical density (OD) range of $0.22-0.35$ at $660 \mathrm{~nm}$. The wild-type $S$. aureus Smith MB2865 and thiazomycin-resistant $S$. aureus MB5832 strains were grown in $10 \mathrm{~mL}$ of LB medium overnight. Overnight growth was adjusted to an optical density of 0.2 at $600 \mathrm{~nm}$. The suspension was then added to molten LB agar in the proportion of $25 \mathrm{~mL} / \mathrm{L}$. The activity was determined by measuring the differences of the zone of clearances observed between the wild type versus the resistant plate. Compound 1 was serially diluted in DMSO 20\% with a dilution factor of 2 to provide 10 compound concentrations starting at $128 \mu \mathrm{g} / \mathrm{mL}$ for all the agar assays. Ten microliters of each compound concentration were applied to the agar plate containing the pathogenic microorganism.

\section{Conclusions}

A thiazolyl pepetide bioactive against MRSA, kocurin (1), has been isolated from cultures of the marine sponge-derived bacterium Kocuria palustris. Its challenging structural elucidation was completed using a combination of spectroscopic and chemical methods, including HRMS, extensive 1D and 2D NMR analysis, MS/MS fragmentation, and chemical degradation and Marfey's analysis of the resulting amino acid residues. The structure herein proposed for the compound corrects that previously reported for PM181104 in a US patent. The identification of a new bioactive compound in a member of 
the Microccocaceae suggests that this family of actinomycetes represents an alternative source for the discovery of new medically relevant small molecules. The relative abundance in marine environments, intra-familiar diversity, and ease of growth of these bacteria makes them an attractive target for the discovery of new antibiotics.

\section{Acknowledgments}

The authors thank the assistance of Catalina Moreno in the preparation of the extracts and Dr. Ignacio Pérez-Victoria for recording the NMR experiments. The polarimeter, IR and NMR equipment used in this work were purchased via two grants for scientific and technological infrastructures from the Ministerio de Ciencia e Innovación [Grants No. PCT-010000-2010-4 (NMR) and INP-2011-0016-PCT-010000-ACT6 (Polarimeter and IR)]. This is contribution No. 13104 from the Institute of Marine and Environmental Technology and contribution No. 4728 from the University of Maryland Center for Environmental Science.

\section{References}

1. Klevens, R.M.; Morrison, M.A.; Nadle, J.; Petit, S.; Gershman, K.; Ray, S.; Harrison, L.H.; Lynfield, R.; Dumyati, G.; Townes, J.M.; et al. Invasive methicillin-resistant Staphylococcus aureus infections in the United States. JAMA 2007, 298, 1763-1771.

2. Bagley, M.C.; Dale, J.W.; Merritt, E.A.; Xiong, X. Thiopeptide antibiotics. Chem. Rev. 2005, 105, 685-714.

3. $\mathrm{Su}$, T.L. Micrococcin, an antibacterial substance formed by a strain of Micrococcus. Br. J. Exp. Pathol. 1948, 29, 473-481.

4. Zhang, C.; Herath, K.; Jayasuriya, H.; Ondeyka, J.G.; Zink, D.L.; Occi, J.; Birdsall, G.; Venugopal, J.; Ushio, M.; Burgess, B.; et al. Thiazomycins, thiazolyl peptide antibiotics from Amycolatopsis fastidiosa. J. Nat. Prod. 2009, 72, 841-847.

5. Palomo, S.; González, I.; de la Cruz, M.; Martín, J.; Tormo, J.R.; Anderson, M.; Hill, R.T.; Vicente, F.; Reyes, F.; Genilloud, O. Sponge-derived Kocuria and Micrococcus spp. as new sources of thiazolyl peptide antibiotics. Mar. Drugs 2013, submitted.

6. Ferrari, P.; Colombo, L.; Stella, S.; Selva, E.; Zerilli, L.F. Antibiotic GE37468 A: A novel inhibitor of bacterial protein synthesis. II. Structure elucidation. J. Antibiot. 1995, 48, 1304-1311.

7. Stella, S.; Montanini, N.; Le Monnier, F.; Ferrari, P.; Colombo, L.; Marinelli, F.; Landini, P.; Ciciliato, I.; Goldstein, B.P.; Selva, E.; et al. Antibiotic GE37468 A: A new inhibitor of bacterial protein synthesis. I. Isolation and characterization. J. Antibiot. 1995, 48, 780-786.

8. Marfey, P. Determination of D-amino acids. II. Use of a bifunctional reagent, 1,5-difluoro-2,4-dinitrobenzene. Carlsberg Res. Commun. 1984, 49, 591-596.

9. Mahajan, G.B.; George, S.D.; Ranadive, P.V.; Mishra, P.D.S.; Eyyammadichiyil, S.S.; Panshikar, R.M.; Sawant, S.N.; Krishna, S.; Sivakumar, M.; Pari, K.; et al. PM181104 and Related Antibacterial Compounds, Production, Pharmaceutical Compositions, and Therapeutic Use. PCT Int. Appl. WO 2007119201A2, 25 October 2007. 
10. Cañedo Hernández, L.M.; Romero Millán, F.; Fernández Medarde, A.; Fernández Chimeno, R.I.; Hidalgo Villar, J.C. Peptides as bioactive compounds. PCT Int. Appl. WO 2012062906A1, 18 May 2012.

11. Walsh, C.T.; Acker, M.G.; Bowers, A.A. Thiazolyl peptide antibiotic biosynthesis: A cascade of post-translational modifications on ribosomal nascent proteins. J. Biol. Chem. 2010, 285, 27525-27531.

12. Montalvo, N.; Mohamed, N.; Enticknap, J.; Hill, R. Novel actinobacteria from marine sponges. Antonie Van Leeuwenhoek 2005, 87, 29-36.

13. Jensen, P.R.; Williams, P.G.; Oh, D.-C.; Zeigler, L.; Fenical, W. Species-specific secondary metabolite production in marine actinomycetes of the Genus Salinispora. Appl. Environ. Microbiol. 2007, 73, 1146-1152.

Samples Availability: Not available.

(C) 2013 by the authors; licensee MDPI, Basel, Switzerland. This article is an open access article distributed under the terms and conditions of the Creative Commons Attribution license (http://creativecommons.org/licenses/by/3.0/). 